\title{
A LINGUAGEM DOS CAMPOS E O URRO DAS FLORESTAS
}

\author{
Marcelo Coutinho \\ Universidade Federal de Pernambuco
}

\section{Resumo}

Este artigo analisa o conceito de "campo disciplinar" em especial quando aplicado à produção artística contemporânea. Questiona até que ponto tal disciplinarização do saber não implicaria em um fechamento epistemológico e autofágico. Quando aplicado à produção artística, o raciocínio disciplinar não levaria a uma domesticação do poder intempestivo da arte?

Palavras-chave: arte contemporânea, epistemologia, filosofia, cultura visual contemporânea.

\section{Abstract}

This article analises the concept of disciplinary field, when applied to a contemporary art piece in particular. It questions to what degree said disciplining of knowledge does not result in an epistemological and autophagic closure. When applied to an artistic production, wouldn't the disciplinary reasoning lead to a domestication of the untimely power of art?

Keywords: contemporary art, epistemology, philosophy, contemporary visual culture.

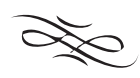

\section{Um campo para a arte}

Não seria o "campo" a metáfora máxima da posse e da demarcação, do que deixou de ser floresta e agora é território arado e produtivo? O "campo" não seria a tentativa de deixar de fora toda uma teratogenia que está sempre para além da ordem do discurso? Este teratismo de que fala Michel Foucault, monstruoso e sem face, que acossa o dizer 
e que o faz ordenar-se e exibir-se como que sendo seu negativo (FOUCAULT, 1999, p. 33$)^{1}$ ?

Assim como a posse da linguagem é o ingresso sublimado do indivíduo na ordem da vida social, os campos disciplinares são a posse e o ingresso na ordem do discurso. Os campos disciplinares são a demarcação de tal posse e a identificação dos territórios de enunciação. São a escrituração e a nomeação dos donos dessa terra e de seus direitos legais sobre ela. São a construção do familiar e a acusação do estrangeiro ou do bastardo que sobre tal território não possui direito, arbítrio e sequer trânsito livre (FOUCAULT, 1999$, p.35) $)^{2}$.

Existiria um campo também para a arte? Haveria também para seu germinar os sulcos de um arado nos quais ela possa ser cultivada e brote em safras? Existiria tal produtividade extensiva na arte moderna que adotou para si, há mais de 100 anos, a ruptura como mito fundador e que se justifica contemporaneamente com as bandeiras do "desvio", da "mestiçagem" e da "desterritorialização"? Teria a arte deixado de ser o emblema máximo da fuga, da brecha aberta pela cultura ocidental contemporânea de onde surgiria um "espaço de exílio" para que "possamos nos proteger das garras do imutável"? (SOUSA, Edson, 2007, p.17)

As "garras do imutável”, imagem criada por Edson Souza, procura tornar nítida, retirar do "pântano", uma evidência constrangedora que, insidiosa, torna-se uma espécie de segunda pele da cultura contemporânea, totalmente incorporada, assimilada e naturalizada. Como diz Souza, trata-se de uma serena "burocratização do amanhã" (SOUSA, Edson, 2007, p.36) ${ }^{3}$.

Gilles Deleuze aponta para esta mesma burocracia do devir acusando a presença de duas maquinarias de controle dentro da produção filosófica: a história da filosofia e a epistemologia. Ambas seriam aparelhos de "repressão do pensamento", servindo a uma "escola de intimidação que fabrica especialistas do pensamento" (DELEUZE, Gilles e Claire Parnet. 2004. p. 22-24).

A epistemologia estabelece um "fora” e um “dentro" de seus domínios. Uma interioridade e uma exterioridade. Para Deleuze o público não especializado é uma das faces desta exterioridade e a ele diz a filosofia: "não me levem muito a sério por que eu penso

$<<<<<<<<<<<<<<<<<<<<<<<<$

1 Sobre a exterioridade dos campos disciplinares diz Michel Foucault: "No interior de seus limites, cada disciplina reconhece proposições verdadeiras e falsas; mas repele, pra fora de suas margens, toda uma teratologia do saber."

2 Michel Foucault, referindo-se ao discurso, diz que a idéia de "verdade" seria um lugar, um lugar de onde o discurso é emitido. O verdadeiro só é assim visto e considerado quando proferido no interior de uma disciplina: "é sempre possível dizer o verdadeiro no espaço de uma exterioridade selvagem; mas não nos encontramos no verdadeiro senão obedecendo às regras de uma 'política' discursiva que devemos reativar em cada um de nossos discursos. A disciplina é um princípio de controle na produção do discurso. Ela lhe fixa os limites pelo jogo de uma identidade que tem a forma de uma reatualização permanente das regras."

3 Diz Sousa: "Desburocratizar o amanhã é fundamentalmente abrir brechas nesta antecipação cruel do tempo". 
em vosso lugar, por que eu dou-vos uma conformidade, normas e regras, uma imagem, às quais podem submeter-se". O especialista da filosofia sabe bem o que quer ao solicitar que este bárbaro, deseducado nas questões filosóficas, não leve a filosofia por demais a sério. O bárbaro calará todo balbucio e dirá para si mesmo: "isso não me diz respeito, isso não tem importância, é assunto de filósofos e das suas teorias puras”. Assim, se fazendo de morta, a burocracia filosófica pode manter-se tranqüila mastigando sozinha seus conceitos, gerando sozinha a imagem do pensamento do mundo. (DELEUZE, Gilles e Claire Parnet. idem. p. 24) ${ }^{4}$.

É possível ir além da história da filosofia e ampliar a fala de Deleuze. Qualquer historia disciplinar arma para seu campo um posto alfandegário forjando assim a figura bárbara do "outro"

Sobre seus supostos pertences a disciplina traça genéticas, impõe genealogias e estabelece hierarquias entre obras e autores. Sua epistemologia elege temas, estabelece métodos e ensina um fazer específico, um ofício para o profissional. Assim, definindo pertencimentos e alheamentos, criando para si esta alteridade, reforça o que seria castiço em sua identidade.

A longa e pura genealogia traçada por todo campo disciplinar é uma das bases para o que Thomas Kuhn chama de "ciência normal". Esta constelação de autores e obras se organiza como o passado legitimador para as novas safras do campo. E será o "paradigma”, este outro conceito criado por Kuhn, que servirá de insumo para o solo onde se darão os plantios e germinarão as safras da "ciência normal" (KUHN, Thomas. 2000. p. $29)^{6}$.

Definido como gerador de uma "constelação de crenças, valores e técnicas partilhadas pelos membros de uma comunidade determinada", o paradigma servirá de elemento primeiro, força agregadora capaz de cimentar a legitimidade desta genealogia puro sangue (KUHN, Thomas. Idem. p. 30). Núcleo lógico consensualmente acordado, horizonte imposto para as possibilidades do olhar, o paradigma é assumido inconscientemente por parte de um grupo social. O próprio processo educacional, de formação profissional do campo disciplinar é expressão deste núcleo cognitivo, verdadeiramente

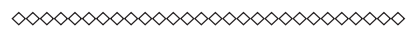

4 Diz Deleuze: "A história da filosofia foi sempre o agente de poder na filosofia e mesmo no pensamento. Desempenhou o papel de repressor: como é que vocês querem pensar sem terem lido Platão, Descartes, Kant e Heidegger e o livro de tal e tal sobre eles?"

5 Será a epistemologia de cada campo ou área que delimitará a pedra fundamental da identidade disciplinar. Será seu exercício que, entre outras coisas, dirá se a pedra fundamental repousa sobre o objeto, sobre o método, sobre o corpus teórico. Será através do método etnográfico que a antropologia se emancipará da sociologia; por sua vez, a sociologia se emancipará da filosofia através da especificidade de seu objeto. E disciplinas mais recentes como a comunicação viverá a debater-se sobre se seriam as mídias o elemento que as diferenciariam do resto das ciências sociais.

6 Diz Thomas Kuhn como sendo a rota para uma "ciência normal”:" (...) ciência normal significa a pesquisa firmemente baseada em uma ou mais realizações científicas passadas. Estas realizações são reconhecidas durante algum tempo por alguma comunidade científica específica como proporcionando os fundamentos para uma prática posterior." 
obscuro. O paradigma se faz carne e passa a olhar o mundo através dos olhos e da cognição do especialista. Tal qual oroboro, o paradigma move-se de forma circular: ele gera uma ciência que, por sua vez, reforça o paradigma que a criou.

Esta estrutura circular e auto-referente é o "mercado de futuros" dos bens simbólicos. Demandas são criadas para o futuro. Assim, o devir perde sua potência desadormecida, seu poder intempestivo, sua fuga originária. Previamente concordado entre produtores e compradores, o futuro tende a cumprir-se, tal qual premonição, sob os grilhões de seu passado ${ }^{7}$. Este mercado de futuros agiria na arte?

Haveria uma alfândega a vasculhar os pertences da arte? A acusar o que lhe é alheio? Sabemos como é estrategicamente útil criar um bárbaro que sirva de molde negativo para a forja de uma identidade incerta ${ }^{8}$.

É certo que a construção do bárbaro não é recente nas artes. Ele surgiu com o modernismo do século XIX e com as vanguardas históricas do século seguinte, fundando o que tantos teóricos e sociólogos da arte chamaram de "crise do gosto", de "fratura entre público e obra" ${ }^{9}$. Mas os códigos desta outra língua se estabilizaram no correr de todo o século XX. E o escândalo aos poucos institucionalizou-se ${ }^{10}$.

A domesticação do escândalo parece ter aberto espaço para a montagem de toda uma maquinaria disciplinar na prática artística. Mesmo que seja impossível para a arte montar-se como uma disciplina científica, dotada de paradigma, teorias e epistemologia

$\infty<\infty<\infty<\infty<\infty<\infty<\infty<\infty<\infty<\infty<\infty<\infty$

7 Uma definição de Mercado de Futuros é: “Compromisso de compra ou venda de determinado ativo numa data futura específica, por um preço pré-estabelecido. O cliente assume, em determinado dia, uma posição comprada ou vendida em um mercado. Dessa forma, ganhará ou perderá de acordo com a oscilação dos preços nos dias posteriores. O comprado ganha com a alta dos preços e o vendido com a baixa." (O Mercado de Futuros e Suas Aplicações. Mesa de Operações BM\&F. Banco Bradesco)

8 Em uma palestra em Recife, na Fundação Joaquim Nabuco, na primeira metade dos anos 90 do século passado, após ser perguntado por um ouvinte sobre o valor que haveria em certa obra de Joseph Beuys e que ele não conseguia verificar, por mais que se esforçasse,o palestrante, crítico de arte, lhe respondeu com uma pergunta. Perguntou ao ouvinte se ele se arvoraria a falar de micro-eletrônica ou de física de sub-partículas. Ao receber como resposta um intimidado "não", o palestrante continuou seu raciocínio dizendo que a arte contemporânea era, assim como a física moderna, um assunto de especialistas, que exigia um conhecimento prévio de sua própria história para ser fruída. A análise da imagem artística do mundo teria passado a ser, portanto, responsabilidade de profissionais especializados em certos campos do saber do mundo contemporâneo.

9 São várias e amplamente conhecidas, entre tantas, as obras de Umberto Eco ("Apocalípticos e Integrados", "A Definição da Arte”), de GilloDorfles ("Novos Ritos, Novos Mitos", "As Oscilações do Gosto", "Elogio da Desarmonia"), de Pierre Francastel ("Problemas da Sociologia da Arte", "O Aparecimento de um Novo Espaço") , de Roger Bastide ("Arte e Sociedade”), de Gregory Battcock ("A Nova Arte”). Estes autores e estas obras, produzidos até o início dos anos 80 do século passado, dedicaram-se a refletir sobre esta nova situação social de ruptura e criação de novos códigos nas artes e do surgimento de novos públicos crescentemente pulverizados.

10 Acho especialmente tocante a descrição feita por Luis Buñuel de seu encontro com André Breton já nos anos 60 do século passado, em Nova York. Cabisbaixo e melancólico, Breton, o homem que um dia sacou o revolver para uma platéia diz para Buñuel, o homem que apedrejou outra platéia: "É triste ter de dizê-lo, caro Luis, mas o escândalo não mais existe." 
próprias, já que seus principais vetores de análise vêm de outras áreas, há sinais claros de um fechamento disciplinar ${ }^{11}$.

O que passou a ser chamado de arte contemporânea construiu também para si um bárbaro. Um segundo tipo de bárbaro, diferente daquele surgido com as vanguardas modernistas. O bárbaro do modernismo era inflamado e revoltado por ver rompido o pacto social da linguagem, por ver violada a sacralidade dos códigos que até pouco tempo eram seus, por ver-se subitamente alijado de parte dos bens de sua própria cultura. $\mathrm{O}$ bárbaro contemporâneo, aquietado e domesticado, assimilou a suposta "separação dos saberes" e se contenta com a parte que lhe cabe dos códigos sociais específicos com os quais foi domesticado. Ao cineasta, as questões plásticas não parecem também suas. Ao escritor as questões do cinema são domínio do cineasta e estas diferem totalmente das literárias. Ao crítico literário os bens de sua cultura também não parecem lhe pertencer e assim ele deixa ao critico de arte ou ao de cinema o cultivo de suas lavouras. Todos desautorizam mutuamente suas vozes. E se um poeta se autoriza a falar uma fala que não é sua é rapidamente colocado em seu devido lugar: o lugar do estrangeiro que não possui os códigos de uma língua específica e por isso não possui a legitimidade necessária ${ }^{12}$.

$\infty<\infty<\infty<\infty<\infty<\infty<\infty<\infty<\infty<\infty<\infty<$

11 Parece-me urgente a feitura de uma finíssima sociologia da arte contemporânea capaz de esmiuçar as informais e quase invisíveis demandas criadas por instituições expositoras, curadores, escolas de arte, mercado de obras e editais públicos e privados de financiamento a artistas.

12 Refiro-me a dois poetas brasileiros, Ferreira Gullar e Affonso Romano de Sant'Anna, que expuseram publicamente seus desgostos e indignações sobre o que genericamente passou a ser chamado de "arte contemporânea". Sem entrar em detalhes diria por hora que o grande problema dos autores é o medonho empreendimento de generalização levado a cabo por ambos. Tratam isso que chamam de arte contemporânea como sendo uma espécie de "movimento" aos moldes das vanguardas históricas, dotadas de alguma coerência. Ambos não se dão conta que o momento atual estaria mais próximo de um ecletismo, onde há não mais que diversidades desconexas que precisariam ser pensadas caso a caso. Porém, a meu ver, ambos podem ser vistos como sinais de saúde dentro do cenário cultural contemporâneo. Os dois poetas tomam para si um fenômeno de seu tempo como sendo seu, e não se calam. Não se recolhem a sua especificidade disciplinar e tratam a cultura como um amplo patrimônio que diz respeito a todos.Penso que antes de impor sobre estes poetas a mesma generalização nefasta que eles fazem sobre as artes visuais, é importante reparar que há efetivamente muita fertilidade em várias de suas questões. Questões estas que, se pesquisadas a fundo poderiam trazer à tona excelentes contribuições para a análise da arte na cultura contemporânea. Darei dois exemplos desta fertilidade. Pergunta-se Gullar em artigo publicado em 2010: "se os movimentos de vanguarda se manifestaram não apenas nas artes plásticas, mas também na poesia, no romance, na música, no teatro, por que só naquelas se manteve dominante até hoje, enquanto as outras artes, depois de absorverem inovações vanguardistas, retornaram, enriquecidas a seu leito natural?" (GULLAR, Ferreira. Do fazer ao Exibir-se. Ilustrada. Folha de S. Paulo. São Paulo, 18 de julho de 2010). Como negar que esta pergunta seja fértil, mesmo que me pergunte o que seria o "leito natural" de uma arte? Diz Sant'Anna sobre a diferença entre obra e escrita nos ensaios de Derrida, Heidegger sobre a pintura "Os Sapatos" de Van Gogh: "Se fôssemos tentar, não digo superpor, mas aproximar tal escrito à obra, veríamos que não se reconhecem, não se ajustam. O quadro descrito ficou aquém ou foi além da obra plástica, o texto realizou uma anamorfose, uma deformação, uma alucinação, uma especulação, fascinante em si, mas distante do original." Como não ver a fertilidade do problemático fenômeno onde o texto crítico não é mais representação de uma obra e sim uma deriva a partir dela? Como não ver que o texto critico assim visto como criação afetada por uma obra estará mais próximo da literatura? Sendo assim, não seria inevitável pensar que a qualidade do texto critico dependeria do talento literário de quem o escreve? (SANT'ANNA, Affonso Romano. O Enigma Vazio: Impasses 
O especialista bem poderia ser visto com esse tipo especial de estrangeiro, a saber, o turista, que passeia, entre a admiração e a náusea, em meio a costumes que não são os seus mas sente-se sempre desautorizado diante desse alheio. $\mathrm{O}$ olhar deste nômade contemporâneo, o turista, ou o especialista, é desencarnado, distante e indireto, sempre defendido por lentes: destes deslocamentos não resta muito mais que fotografias. A figura do "observador participante" da antropologia britânica moderna inexiste para as incursões entre disciplinas feitas pelo especialista ${ }^{13}$.

Em um texto do artista, crítico e curador Ricardo Basbaum vê-se claramente os efeitos desta epistemologia de controle aplicada à arte. Basbaum dirá sobre o vídeo, a fotografia, o cinema e as artes visuais:

"Todos estes meios, hoje, configuram-se como disciplinas autônomas, dotados de linguagem, objeto, meios técnicos e conceitualizações que lhes são próprios, de modo que podemos considerá-los como diferentes saberes (...)"(BASBAUM, Ricardo. 2007. p. 23-24) $)^{14}$

Submerso no paradigma próprio ao conhecimento de tipo disciplinar,este raciocínio não se dá conta que "meios", "linguagens", e "conceitualizações" são peças dentro de um sistema social de significações que estabelecem entre si uma dinâmica circular auto-referente.

Esta circularidade é muito semelhante ao que ocorre na ciência. Edgar Morin descreveu exaustivamente este ponto cego, esta imensa margem de incerteza que constitui toda produção de conhecimento, desenhando a inevitável circularidade existente entre

da Arte e da Crítica. Rio de Janeiro: Ed. Rocco, 2008. p.139)

13 A "observação participante" nasce com o pai da antropologia social inglesa BronislawMalinowsky em sua famosa etnografia "Os Argonautas do Pacífico Sul", de 1922. O antropólogo William Foote-Whyte aprofunda este método usando-o não em culturas exóticas, porém em sub-grupos culturais de sua própria cultura. Em seu estudo da comunidade periférica italiana de Cornerville, Foote-Whyte, professor de Harvard, vê-se obrigado a misturar-se com seu campo a ponto de passar a falar "(...) mais entusiasticamente, engolindo os finais das palavras e gesticulando muito." E continua: "Enquanto estava em Cornerville, durante as minhas visitas a Harvardeu me via de língua travada. Eu simplesmente não podia manter discussões sobre relações internacionais, natureza da ciência e assim por diante, nas quais antes me sentia à vontade". De "observador", ou "sujeito" da pesquisa, o professor de Harvard tornou-se secretário do Clube Comunidade Italiana e passou a participar das "discussões de rua sobre baseball e sexo" junto com seus "objetos" de estudo. (William Foote-Whyte. Treinando a Observação Participante. In GUIMARÃES, Alba Zaluar. Desvendando Máscaras Sociais. Rio de Janeiro: Ed. Francisco Alves. p. 82-83)

14 Logo mais adiante, Basbaum usa Foulcaut e Deleuze para lembrar que haveria "agenciamentos" a serem levados em conta. Porém, fica claro que, para o autor, estes agenciamentos ocorrem entre linguagens e meios do interior do sistema de arte e nunca de elementos vindos de fora do sistema. Logo mais a frente Basbaum deixa clara sua posição de delimitação entre linguagens artísticas: "Assim, os diferentes meios de produção de visualidade podem ser particularizados através da prática específica empregada na realização de tal agenciamento". 
paradigma, ciência e técnica, na qual o paradigma cria a ciência que cria a técnica que, por sua vez, materializará o paradigma e redundará no reforço da ciência (MORIN, Edgar. Ed. Sulina, 1999).

Sem reparar nesta autofagia circular, Basbaum parece optar por manter-se nos limites do chamado "campo da arte" quando, por exemplo, se propõe a construir uma história para o surgimento de obras de artes plásticas que passam a usar a palavra e o texto como elementos constitutivos. Para o autor, o enlaçamento entre texto e imagem não indicaria um tipo de contaminação entre "campos" ou o nascimento de um híbrido cuja história estaria ainda por ser feita. Para Basbaum o início desta genealogia está no interior da própria história particular do "campo das artes plásticas", especificamente da crítica de arte que, evoluindo, "migra para dentro da obra" (BASBAUM, Ricardo. Idem, p. 30 a 31$)^{15}$.

No sistema de arte, críticas reforçam obras que, por sua vez, reforçam criticas que novamente retroagirão sobre obras e teorias. Este movimento circular, entre outras características, opera no reforço da circunscrição do tal campo. A operacionalidade deste sistema é, em termos comunicacionais, o elemento da redundância. Todas as partes desta estrutura redundam sobre si próprias na afirmação de uma identidade. Identidade que se monta sempre na afirmação do mesmo e nunca da diferença.

\section{Citação e autofagia}

Nesta trilha de indagações recordo de uma performance recente da irlandesa KiraO'Reilly chamada Indo Dormir com um Porco. E pergunto-me: como é possível que ali nada se desvele, nenhuma desmedida se apresente além de uma bem assentada topografia do campo da arte, muito bem arada, sem qualquer tremor ou abalo?

Se o que funda a arte é um perene processo de reinvenção de linguagem para que assim algo inaudito ecloda, por que a ação I LikeAmericaandAmericaLikes me de Joseph Beuys parece servir de solo seguro para a performer KiraO'Reilly e seu porco? Dirão alguns: trata-se de um trabalho montado sobre a citação, um trabalho que comenta de forma irônica a própria história das artes plásticas. Se assim for, então onde ficaria a jus-

$\infty<\infty<\infty<\infty<\infty<\infty<\infty<\infty<\infty<\infty<\infty<\infty$

15 Para o autor as relações entre obra e enunciado textual se iniciam tendo o texto crítico como olhar distanciado, como a consciência e a verdade legitimadora da imagem. Logo depois, com Baudelaire, a crítica de arte se aproximaria da obra e passaria a ser "parcial, apaixonada, política", construindo-se a partir do mesmo impulso que forjaria a obra. Por fim, num terceiro momento, passa a habitar a própria obra, numa "cumplicidade absoluta". Basbaum inclusive aposta bastante alto quando diz que este processo evolutivo seria a diferença entre o momento moderno (época dos manifestos) e o pós-moderno (época de obras que usam textos). Como se vê, não há qualquer interesse em supor outras linhas evolutivas, externas ao tal "campo" e que estariam agindo sobre obras e autores. Penso, por exemplo, na influência da poesia de Jules Laforgue sobre Marcel Duchamp e no uso que fez de textos e palavras em suas obras. Por mais que o artista aponte tal influência a todo momento não parece ser algo de interesse ao raciocínio especialista.. 
tificativa de "desterritorialização" e "hibridismo" que se mantêm, ao menos no discurso, como sendo a pedra fundamental da arte contemporânea?

O’Reilly não se refere a operações de ironia ou citação, tampouco os textos críticos que tive acesso parecem se deter neste tipo de procedimento. A obra, assim, parece manter-se subliminar, protegida sob a sombra frondosa de uma história recente da arte ocidental.

Porém, o Construtivismo Rural de Nelson Leirner, que refaz em couro de boi obras do movimento construtivo, deixa clara essa intenção de comentário e ironia cáustica. Refazer o Espaço Modelado de Lygia Clark no preto e branco do couro de boi, o mesmo couro que recobre cadeiras de gosto duvidoso, seria como quer Tadeu Chiarelli, uma "sarcástica e direta sátira" aos valores entronizados do próprio circuito de arte.

Mas como uma obra que se quer crítica a valores de entronização, e quer supostamente operar uma desconstrução do sistema de arte é exibida na Bienal de Veneza de 1999, serve de "parâmetro" para artistas emergentes em uma das mostras do Panorama da Arte Brasileira 99 e é adquirida pelo MAM-SP, um dos museus mais tradicionais do Brasil? Para Tadeu Chiarelli não há qualquer contradição:

"Ora, no caso de Nelson Leirner e dos trabalhos que apresenta neste Panorama o que o museu poderia fazer? Recusá-los? A crítica à instituição, afinal está tão institucionalizada quanto a própria arte... e, além do mais, as peças apresentadas pelo artista podem ajudar numa compreensão maior e extremamente crítica do próprio circuito..." (CHIARELLI, Tadeu. Panorama 99: O Acervo como Parâmetro. In Panorama da Arte Brasileira 1999. Museu de Arte Moderna de São Paulo, 1999. p. 38)

Neste oroboro, onde a arte narcisicamente afoga-se em seu próprio reflexo, parece-me igualmente emblemático que a artista Laura Vinci defenda sua Instalação "Ainda Viva" das críticas do jornalista Luciano Trigo e do poeta Ferreira Gullar se utilizando das armas vindas de seu campo de especialista:

"A única coisa que Gullar sabe sobre o trabalho é que nele existem '300 maçãs' expostas ao apodrecimento, o que lhe pareceu suficiente para tecer considerações ácidas sobre a obra e o estado geral da arte. Imagino então se ele soubesse que não são 300, mas 7.000 maçãs. Se ele visse que mesmo assim, numa dimensão de Ceasa, uma maçã é uma maçã que sempre lembrará Cézanne. Que postas numa superfície de mármore, que tem a dignidade do altar, da lápide e da tela branca, elas estão ali falando da tradição da natureza-morta na pintura. Que elas apodrecem em conjunto sem perder a beleza e exalando um perfume embriagante. Talvez ele se lembrasse que "natureza-morta" se diz em inglês "still life", vida parada, ou ainda vida. Que 
isso é uma pergunta sobre o destino da arte, e não uma confusão da arte com o lixo." (Laura Vinci. http://www.canalcontemporaneo.art. br/brasa/archives/001544.html)

É curioso que nunca me viria à mente em primeira instância que "uma maçã sempre lembrará Cézanne". Nunca pensaria em uma "tela branca" como análoga ao mármore ou ao "futuro da arte". A história da maçã ou do mármore é longa demais, transcende qualquer still life e vai para muito além da arte. Antes, pensaria em uma morte duplicada, onde a carne apodrecida não deixaria de si sequer sua semente que, sobre o mármore, nunca brotará. Ou ainda, pensaria em todas as maçãs nunca mordidas, que nunca chegaram a oferecer ao homem sua gloriosa queda...

Estes são alguns exemplos entre inumeráveis outros possíveis. Invariavelmente, o horizonte de grande parte da produção de arte hoje é a própria arte. E a citação passou a ser um dos dados legitimadores de boa parte da chamada arte contemporânea. Seja esta citação explícita ou dissimulada.

A replicação de estratégias de montagem consagradas pela história recente da arte é uma das formas dissimuladas de citação. Vê-se em várias obras atuais o uso claro de uma aparência de espacialização minimalista, de uma documentação aos moldes de landart ou da arte conceitual. O que um dia foi registro e documentação de um pensamento ou ação que não possuía suporte possível, que exatamente por não passar de documentação um dia abalou o sistema econômico de museus, galerias, vendedores e compradores, é agora mostrado como obra, como forma fetichizada.

Oblitera-se a força instauradora que em 1962 forjou as pequenas pinturas de datas, distribuídas monotonamente nas paredes do espaço expositivo ou mesmo a potência exigente que agiu sobre os cartões postais enviados de OnKawara. Negligencia-se a pressão inaugural das unidades repetidas de 24 tubos de fibra de vidro aparentemente iguais, feitos à mão por Eva Hesse em 1968.

Que estranha força é essa que leva alguns a repetir, não mais que repetir, depois de 40 anos, o mesmo emasculamento de Vito Acconci que, em 1967, esconde seu pênis entre as pernas fazendo dele uma vagina? Ou reproduzir a fórmula da repetição serializada do minimalismo apenas pela superfície, juntando tijolos sobre o chão de uma galeria, na mesma configuração de "Equivalent III", de 1964, de Donald Judd?

Esta espécie curiosa de formalismo pós-moderno apropriou-se fartamente também da riquíssima operação de descontextualização de objetos, cenas, ações, ou eventos, nascida com o Dada, o Surrealismo e o ready-made duchampiano, retomado e ampliado com imensa fertilidade pelas últimas vanguardas dos anos 60 do século XX.

Estas obras à sua época não eram meras operações de montagem. Tampouco eram procedimentos estáveis em seus contextos. Eram verdadeiramente inaugurais para o dizer. Ao que parece, acessar a história da arte através da aplicação de uma estratégia de 
visualidade já estável e consagrada indica, de seu modo dissimulado, o mesmo princípio de citação e remake.

Sendo assim, seríamos obrigados a admitir que aquilo que parte das obras contemporâneas visa é um campo bastante bem demarcado: a própria arte, sua história, sua crítica, seus métodos construtivos e formas de linguagem já previamente reconhecíveis.

Para Hans Belting um dos traços de caráter da arte contemporânea seria exatamente esta "rememoração cultural", este "remake". Para ele, "em nossa cultura compartimentada distribuída em tantas especialidades e grupos profissionais", a teoria e a crítica de arte acabam por revelar "mais sobre a disciplina em que é exercida do que sobre a arte da qual trata”. Diz Belting mais adiante:

"O progresso é trocado pela palavra remake. Façamos novamente o que já foi feito. A nova versão não é melhor, mas também não é pior -e, em todo caso, é uma reflexão sobre a antiga versão que ela (ainda) não poderia empregar." (BELTING, Hans. 2006. p.31)

De forma lamentosa, com a fala baixa e monótona, como que esmagada pelo peso mortífero próprio da fala do melancólico, fala fraca e adoecida que sucumbe a falência prévia que forja qualquer discurso, Hans Belting sugere que estaríamos vivendo uma época que não permite mais prefácios. Nada mais seria apresentado, inaugurado, abrindo-se como o horizonte para o porvir da história da arte. Hoje, seríamos conduzidos a escrever não mais que epílogos, textos de fechamento, de conclusões e despedidas ${ }^{16}$.

A citação, a rememoração, o remake, que para Belting seria um dos sinais de um "fim da história da arte", a meu ver seria um, entre outros sintomas, de uma arte que passou a se ver como disciplina e, como tal, efetuou um mortífero fechamento disciplinar. Tal como uma ciência tradicional, trata-se da construção de um discurso que tende a nascer legitimado (BELTING, Idem. p.31) ${ }^{17}$.

\section{A identidade e a melancolia do idêntico}

É como se o conhecimento subdividido em áreas e falas autorizadas de especialistas replicasse a voz de Hegel sobre "a consciência-de-si” e precisasse sempre partir da

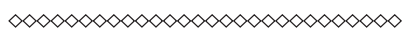

16 Diz Belting: "Onde não se descobre nada de novo e o velho não é mais o velho, sempre se supõe o epílogo.”(Idem. p.17)

17 O papel do ensino da arte como agente deste fechamento disciplinar é acusado por Belting: “(...) na Alemanha o número de estudantes universitários constitui um fator de mercado no planejamento de editoras. O desenvolvimento da história da arte é evidenciado quando a editoiraMacmillan anuncia um dicionário de arte que deverá conter, em 34 volumes, 533.000 entradas sobre arte mundial.”(Idem, p.29) 
exclusão do outro, da alteridade, para se efetivar e assim construir a sua identidade ${ }^{18}$.

Mas já foi fartamente dito que o princípio da identidade é um dos reflexos de outro princípio, este mais profundo, fortemente enraizado na cultura ocidental moderna: a representação. É ela que impõe os "universais", uma modelização apriorística sobre o devir e sobre o que difere. E assim, inibe, desautoriza e subordina a proliferação da diferença ao idêntico .(DELEUZE, Gilles. 2006. p. 105) ${ }^{19}$.

A quebra destes ciclos tautológicos de repetição é algo que vai, portanto, muito além da arte. São muitos os autores que se dedicaram ao tema da diferença e da quebra de tal padrão de repetições. Na trilha de uma redefinição da utopia diz Edson Sousa, em consonância com o que me interessa e que penso ser aplicável a arte:

"Portanto, o saber vem por vezes legitimar a reclusão que nos impomos diante do desconhecido. (...) Criar é abrir descontinuidades, interrupções no fluxo do mesmo."

E mais adiante:

“(...) a passividade anda de mãos dadas com a tristeza que constata que tudo está sempre tão igual, e que há, enfim, alguém que pensa por nós, que faz por nós, e o que é pior, que vive por nós". (SOUSA, Edson. Idem p. 19-20)

Desse adoecimento que surge da imobilidade descrita pelo autor, penso se não seria tempo de investigarmos até que ponto a disciplinarização do conhecimento não causaria certa "passividade entristecida", vinda da constatação de que a voz da disciplina é anterior a minha, que é ela quem me fornece os temas dignos a serem investigados, quem elege previamente para mim os referenciais teóricos mais adequados e que será ela quem dará legitimidade a minha voz.

Há leis demais nos campos. E essas leis são avessas a ecologia e a qualquer teratogênese que dela brota. Nas florestas não há lei. No máximo há hábitos, como sugere

$\infty<\infty<\infty<\infty<\infty<\infty<\infty<\infty<\infty<\infty<\infty<$

18 Diz Hegel sobre a identidade: "De início, a consciência-de-si é ser-para-si-mesmo, igual a si mesma mediante o excluir de si todo outro. Para ela, sua essência e objeto é o Eu; e nessa imediatez ou nesse ser-para-si é um singular. O que é Outro para ela, está como objeto inessencial, marcado com o sinal negativo. Mas o Outro é também uma consciência-se-si (...)”. E mais adiante continua a descrição assustadora desta batalha sangrenta: “(...) a relação das duas consciências-de-si é determinada de tal modo que elas se provam a si mesmas e uma a outra através de uma luta de vida ou morte. Devem travar essa luta, porque precisam elevar à verdade, no Outro e nelas mesmas, sua certeza de ser-para-si.” (HEGEL, G.W.F. Apud PETERS, Michael. Pós Estruturalismo e Filosofia da Diferença: Uma Introdução. Belo Horizonte: Ed. Autêntica. 2000.p.56.)

19 A demolição da representação como operador cognitivo matriz da cultura ocidental foi desenvolvido durante todo o século XX, tendo Heidegger, nos anos 30, como ponta de lança a partir de sua idéia de "diferença ontológica" e Gilles Deleuze, nos anos 60 e 70 como aquele que irá aprofundar, criar e radicalizar uma "filosofia da diferença". Este caminho será fértil e abrirá a filosofia e as ciências sociais européias e norte-americanas posteriores, por exemplo, para um novo olhar sobre as culturas construídas na periferia dos grandes centros e, por isso, organicamente desviantes do modelo europeu. 
o biólogo Rupert Shaldrake ${ }^{20}$. E teratos é o nome grego dado à este hábito que a floresta tem de criar periodicamente monstruosidades, anomalias embrionárias, que desestabilizam o horizonte de nosso olhar.

Não à toa me refiro aos argumentos de certas filosofias. Elas me levam a pensar a arte na direção de uma ecologia e não de uma epistemologia.

Ali, nas zonas indeterminadas deste contágio ecológico, conceituações, teorizações e obras estendem suas ramas umas sobre as outras e neste fértil parasitismo não reconhecem bem o que seria um "fora" ou um "dentro".

Trata-se de um devir na direção de algo diverso porém compossível. É do interior desta deriva de com possibilidades que se dão as aproximações naturais à própria criação artística. Este estado de movimento garante a situação de abertura necessária para estabelecer com alteridades disciplinares sempre outras contaminações.

Se fizéssemos uma teratologia das artes seriamos obrigados a ver que algo insiste em proliferar entre espécies, entre categorias, confundindo "saberes", “objetos", "meios técnicos" e "conceitualizações". Pois aquilo que gerou a obra - e que a meu ver é o que mais interessa - continua ali, inquieto na vastidão de seu silêncio, a proliferar brasas e perguntas.

A meu ver, as brasas de tais perguntas podem acender quando, em movimento, atravessamos as fronteiras de campos e linguagens previamente delimitados. Longe do idêntico e das identidades que emergem dos universais, me pergunto se as identidades disciplinares, antes de delimitarem bordas e limites fixos não seriam um processo inconcluso, cujas fronteiras não são estáveis. Caso sobre elas nos debruçássemos com atenção veríamos que nelas nada perdura, que nelas tudo é devir.

Ao invés de pensar na metáfora do "campo", poderíamos propor uma outra, mais orgânica e viva: a metáfora do "ecossistema" e das "espécies". As espécies que vivem em um ecossistema são distintas entre si. Mesmo sendo distintas, estão inextricavelmente abertas ao seu próprio movimento. Este movimento é uma deriva que atenta, a cada movimento, contra sua própria integridade.

$\infty<\infty<\infty<\infty<\infty<\infty<\infty<\infty<\infty<\infty<\infty<\infty$

20 RUPERT, Sheldrake. A Presença do Passado: Os Hábitos da Natureza. Lisboa: Instituto Piaget, 1996. p.34. 


\section{Referências bibliográficas}

FOUCAULT, Michel. A Ordem do Discurso. São Paulo: Ed. Loyola, 1999.

SOUSA, Edson Luis André de. Uma Invenção da Utopia. São Paulo: Lumme Editor, 2007.

DELEUZE, Gilles e Claire Parnet. Diálogos. Lisboa: Relógio D’Água Editores, 2004.

KUHN, Thomas. A Estrutura das Revoluções Científicas. São Paulo: Ed. Perspectiva, 2000.

DELEUZE, Gilles. Diferença e Repetição. Diferença e Repetição. São Paulo: Graal, 2006.

BUÑUEL,Luis. Meu Último Suspiro. São Paulo: Ed. Nova Fronteira. 1992.

SANT'ANNA, Affonso Romano. O Enigma Vazio: Impasses da Arte e da Crítica. Rio de Janeiro: Ed. Rocco, 2008.

GULLAR, Ferreira. Do fazer ao Exibir-se. Ilustrada. Folha de S. Paulo. São Paulo, 18 de julho de 2010.

William Foote-Whyte. Treinando a Observação Participante. In GUIMARÃES, Alba Zaluar. Desvendando Máscaras Sociais. Rio de Janeiro: Ed. Francisco Alves.

BASBAUM, Ricardo. Além da Pureza Visual. Porto Alegre: Ed. Zouk.,2007.

MORIN, Edgar. O Método III- O Conhecimento do Conhecimento. Porto Alegre: Ed. Sulina, 1999.

CHIARELLI, Tadeu. Panorama 99: O Acervo como Parâmetro. In Panorama da Arte Brasileira 1999. São Paulo: Museu de Arte Moderna de São Paulo, 1999.

Laura Vinci. (http://www.canalcontemporaneo.art.br/brasa/archives/001544.html)

O Mercado de Futuros e Suas Aplicações. Mesa de Operações BM\&F. Banco Bradesco.

BELTING, Hans. O Fim da História da Arte. São Paulo: Ed. Casacnaify, 2006.

HEGEL, G.W.F. Apud PETERS, Michael. Pós Estruturalismo e Filosofia da Diferença: Uma Introdução. Belo Horizonte: Ed. Autêntica. 2000. 